\title{
Seismic vulnerability assessment of building stock of Malakand (Pakistan) using FEMA P-154 method
}

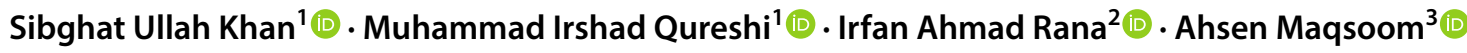

Received: 25 June 2019 / Accepted: 13 November 2019 / Published online: 16 November 2019

(c) Springer Nature Switzerland AG 2019

\begin{abstract}
Earthquakes have caused huge infrastructural damages along with loss of lives in the recent past. Continuous subduction of the Indian plate beneath the Eurasian plate has made Pakistan a seismically active region in the world. Malakand, located in the Khyber Pakhtunkhwa Province of Pakistan, is declared at high earthquake risk by the National Disaster Management Authority of Pakistan, warranting a seismic vulnerability assessment study for its existing building stock. Vulnerability assessment of a representative sample of different building use-types was carried out using the rapid visual screening (RVS) procedure of FEMA P-154. The sample size was calculated based on Yamane formula. RVS sheets are used to calculate structural scores, and likely seismogenic damage is depicted as a function of damage grades of European Macro Seismic Scale. Of the building stock inspected, it was observed that almost half of the buildings fall in damage grade 4 and 5 , implying a strong probability of heavy structural and non-structural damages in the case of future earthquake occurrence. Government school buildings were found to be less vulnerable than private counterparts. Most of the commercial buildings were not constructed according to building code, making them highly susceptible to damage. Based on the results of vulnerability assessment of building structures, the article recommends implementation of building codes which can lead to a decrease in infrastructural damages and economic losses in the wake of a future seismic event.
\end{abstract}

Keywords Damage grades · Rapid visual screening $\cdot$ Risk reduction · European Macro Seismic Scale

\begin{tabular}{llll}
\multicolumn{2}{l}{ Abbreviations } & BCP SP-07 & Building code of Pakistan Seismic Provision \\
RVS & Rapid visual screening & & 2007 \\
DG & Damage grade & SS & Structural score \\
PMD & Pakistan Meteorological Department & CM & Confined brick masonry \\
NDMA & National Disaster Management Authority & UCM & Unconfined brick masonry \\
KPK & Khyber Pakhtunkhwa & CBM & Confined block masonry \\
$S_{S}$ & Short-period spectral acceleration & UCBM & Unconfined block masonry \\
$S_{1}$ & Long-period spectral acceleration & CSM & Confined stone masonry
\end{tabular}

Electronic supplementary material The online version of this article (https://doi.org/10.1007/s42452-019-1681-z) contains supplementary material, which is available to authorized users.

$\triangle$ Muhammad Irshad Qureshi, irshad.qureshi@uettaxila.edu.pk; Sibghat Ullah Khan, sibghatullah.khan@students.uettaxila.edu.pk; Irfan Ahmad Rana, iarana@nit.nust.edu.pk; Ahsen Maqsoom, ahsen.maqsoom@ciitwah.edu.pk|'Department of Civil Engineering, University of Engineering and Technology Taxila, Taxila 47080, Pakistan. ${ }^{2}$ Department of Urban and Regional Planning, School of Civil and Environmental Engineering (SCEE), National University of Sciences and Technology, Islamabad 44000, Pakistan. ${ }^{3}$ Department of Civil Engineering, COMSATS University Islamabad Wah Campus, Wah Cantt 47040, Pakistan. 
UCSM Unconfined stone masonry

US United States

\section{Introduction}

Damages from earthquakes and floods are on the rise [1], resulting in a number of fatalities and loss of assets associated with them [2]. It is not possible to prevent natural hazards from occurring; however, adverse impacts associated with them can be minimized to a considerable level by employing preventive strategies. Earthquakes can have a severe impact on the built environment, and damages largely depend upon building types, materials, construction practices, and institutional policies [3]. Thus, the number of casualties, injuries, and loss of assets in an earthquake can be greatly affected by the vulnerability of the existing building stock. Different types of buildings like residential, commercial, schools, etc., can have varied infrastructural damages and fatalities. Therefore, exploring the seismic vulnerability of buildings can help in understanding the multifaceted concept of vulnerability and, in the larger picture, disaster risk.

Vulnerability is defined as the inability to resist a hazard, and seismic vulnerability is the probability of likely damages of buildings, services, infrastructures, etc., due to earthquakes. Seismic risk assessment is composed of three major components: hazard, vulnerability, and exposure [4]. Seismic hazard can be measured by deterministic or probabilistic seismic hazard analysis method [5]; however, it cannot be controlled. On the other hand, vulnerability and exposure of a community can be controlled and minimized to a considerable level to reduce overall seismic risk. Seismic vulnerability of a structure is the measure of its seismic capacity and hence is found to be one of the major parts of seismic risk assessment $[6,7]$. Assessing the vulnerability of a structure gives an indication that whether a detailed evaluation and retrofitting are required.

Numerous procedures and methods are available in the literature for seismic vulnerability assessment of existing building stock $[8,9]$. These range from the most complex procedures based on finite element analysis of buildings to simpler ones like RVS procedure based on a sidewalk survey from the street or inside a building. Researchers had used the detailed nonlinear procedure for vulnerability assessment in the past $[10,11]$, however it is timeconsuming and therefore can be employed on a limited number of buildings. RVS is relatively inexpensive, and a large number of buildings can be surveyed in a limited period of time. Researchers have developed and used the RVS procedure worldwide for vulnerability assessment of buildings [12-21]. In the absence of accurate data like material properties, less expertise in nonlinear modeling of buildings, low manpower, etc., RVS is an effective way to identify seismically vulnerable buildings.

Continuous subduction of the Indian plate beneath the Eurasian plate has made Pakistan one of the most seismically active regions in the world [22]. Pakistan Meteorological Department (PMD) reports that in the past 50 years, 58 earthquakes of considerable magnitude struck Pakistan and caused serious damages to assets and lives [23]. However, six dangerous earthquakes to have struck in the region (Pakistan) are Kangra earthquake in 1905, Quetta earthquake in 1935, Makran earthquake in 1945, Kashmir earthquake in 2005, Southern Pakistan earthquake in 2011, and Awaran earthquake in 2013 [23-27]. On average, Pakistan may experience a damaging earthquake every 10 years, which can result in huge socioeconomic losses, and cause devastation to cultural heritage sites [28]. The 2005 Kashmir earthquake resulted in 73,000 casualties, left 80,000 injured and 2.8 million people without shelter [29]. Total losses due to the Kashmir earthquake were estimated at around US\$ 5198 million [29]. Huge losses due to earthquakes can be attributed to lack of awareness, preparedness, and enforcement of building codes [30,31]. These earthquakes-induced losses are also due to the lack of effective policies and their implementation. Due to huge losses of lives and infrastructure in the past, there is a dire need for seismic risk assessment of buildings in seismicprone districts of Pakistan.

Generally, buildings in Pakistan are non-engineered or semi-engineered and are constructed without following earthquake-resistant design. About $90 \%$ of the existing building stock in the country is non-engineered masonry [32]. As compared to engineered buildings, limited research work is performed on non-engineered buildings [33]. Non-engineered buildings behave satisfactorily against gravity loads but are less resistant against lateral loads. Therefore, it is imperative to assess the vulnerability of these buildings in a high-earthquake-risk area, to estimate the probable extent of damages and to suggest appropriate disaster risk reduction measures.

Malakand was chosen as a case study area as it is declared a high-earthquake-risk region by the National Disaster Management Authority (NDMA) of Pakistan [34]. The aim of this study is to carry out a vulnerability assessment of different building use-types in an earthquake-prone district Malakand located in the Khyber Pakhtunkhwa (KPK) province of Pakistan. This study is an important step to provide useful information to concerned authorities, researchers, and other institutions, and can be used as a baseline to design effective risk reduction policies to decrease losses associated with earthquakes in the future.

Malakand is a district of KPK province, Pakistan. It has a latitude of $34^{\circ} 30^{\prime} 10.95^{\prime \prime} \mathrm{N}$ and has a longitude of 
$71^{\circ} 54^{\prime} 16.43^{\prime \prime} \mathrm{E}$. It is of great strategic importance as it acts as a gateway to Dir, Bajaur, Swat, and Buner, and is mostly surrounded by mountains. Area of district Malakand is $952 \mathrm{Km}^{2}$, with an estimated total population of 720,295 [35]. It is divided into two subdivisions named Sam Ranizai and Swat Ranizai. The population of Sam Ranizai and Swat Ranizai is 304,112 and 416,183 , respectively [35]. The northern part of Malakand is hilly, and urban growth is spurting from foothills to plain areas. The population is concentrated in core/interior of urban settlement with relatively higher population density than surroundings, with linear urban expansion along main roads in the outskirts. Building code of Pakistan Seismic Provision 2007 (BCP SP-07) has placed Sam Ranizai in Seismic Zone 2B and Swat Ranizai in Seismic Zone 3 [36]. Sam Ranizai and Swat Ranizai are at moderate- and high-earthquake hazards, respectively. Peak ground accelerations of seismic

Table 1 Seismic zones of Pakistan [36]

\begin{tabular}{ll}
\hline Seismic zones & $\begin{array}{l}\text { Peak horizontal } \\
\text { ground accelera- } \\
\text { tion }(\mathrm{g})\end{array}$ \\
\hline 1 & $0.05-0.08$ \\
$2 \mathrm{~A}$ & $0.08-0.16$ \\
$2 \mathrm{~B}$ & $0.16-0.24$ \\
3 & $0.24-0.32$ \\
4 & $>0.32$ \\
\hline
\end{tabular}

zones of Pakistan are shown in Table 1. A map of Pakistan representing the case study area is shown in Fig. 1.

\section{Methodology}

\subsection{Rapid visual screening}

RVS method is based on a sidewalk survey from the street or inside a building in which a trained screener identifies the load resisting system and captures some of the attributes which affect the seismic performance of a structure negatively or positively. These attributes include plan asymmetry, vertical irregularity, cracks, wall openings, building height, construction quality, etc. Nonlinear finite element analysis is the most accurate procedure to compute seismic vulnerability of buildings of an area; however, it is not possible to analyze every building structurally to predict its seismic performance as it is technically complex, requires expertise in nonlinear modeling, computationally expensive, and time-consuming. To deal with a large stock of building, RVS procedure, which does not require any structural calculations, provides a fast and effective alternative to assess the seismic vulnerability.

RVS has many applications in the fields of Disaster Management, Civil Engineering, and Urban Planning. Application of RVS in Disaster Management is that it gives an assessment of the vulnerability of the total building stock of an area and indicates whether a massive risk reduction
Fig. 1 Map of Pakistan representing Malakand [34]

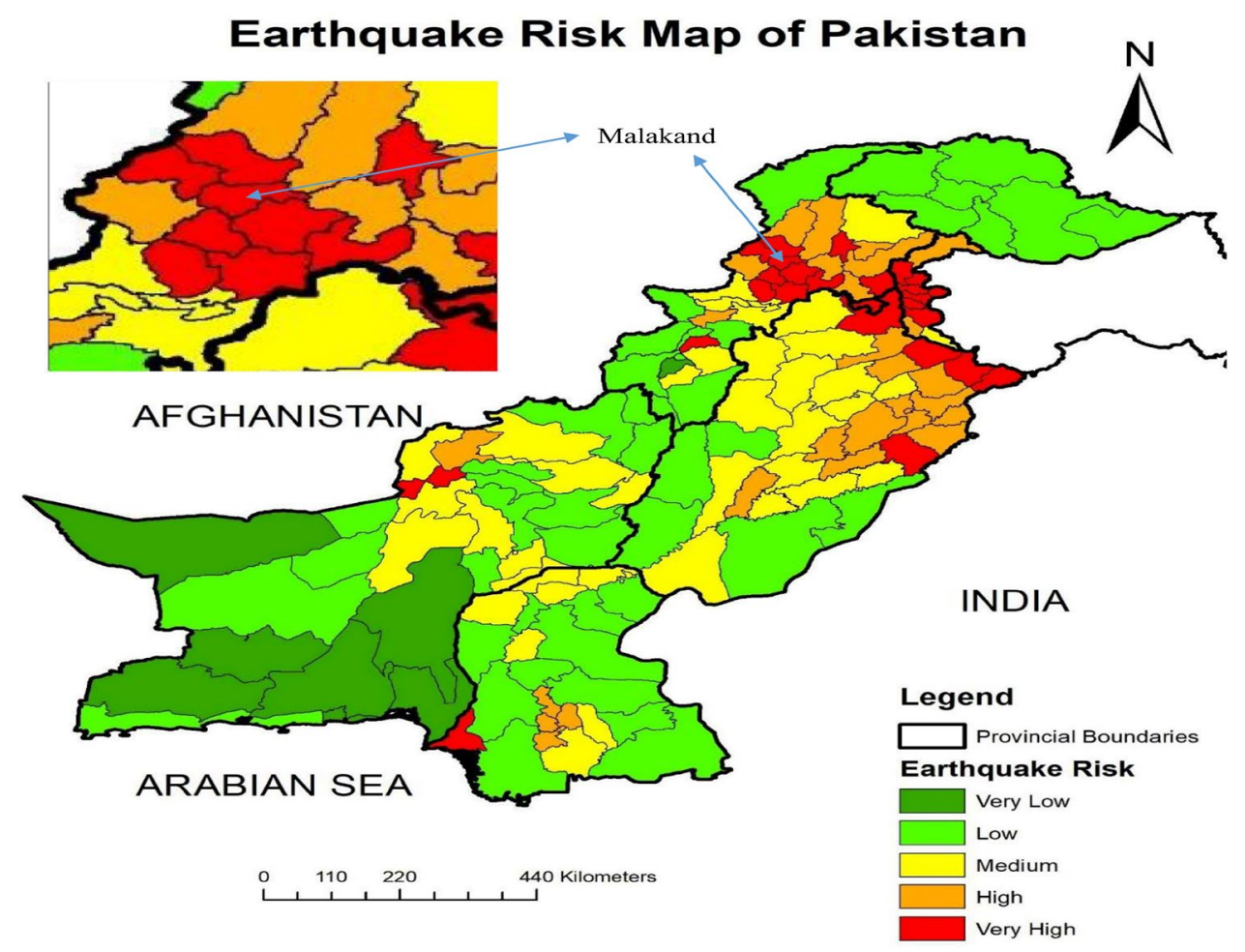

SN Applied Sciences A SPRINGER NATURE journal 
drive is needed or not. In the field of Civil Engineering, RVS studies help Structural Engineers to identify vulnerable buildings for further detailed evaluation. RVS studies help Urban Planners to design effective policies to ensure risk reduction in the future.

There are different RVS methodologies available in the literature developed by different countries for their local conditions; however, they can be adapted to any area after certain modifications according to local conditions. Some of the seismic vulnerability assessment methodologies developed by different countries are discussed in detail by Alam et al. [37]. However, in this study, the method developed by the United States (US) named FEMA P-154 was adopted without any improvements and changes for local conditions, as it accounts for all building types to be evaluated in the case study area. RVS methods, including FEMA, are used by researchers in India as well for vulnerability assessment $[38,39]$.

FEMA P-154 provides a relatively quick and inexpensive method for identifying a list of seismically hazardous buildings without performing detailed evaluation of individual building. Firstly, a base score is assigned to a building based on its lateral load resisting system which reflects the estimated likelihood that the building will collapse if subjected to MCE ground motion--an earthquake having a $2 \%$ probability of exceedance in 50 years. The base score is then modified negatively or positively by some critical parameters to get final Structural Score (SS). SS of 1 reflects that a building probability to collapse against MCE earthquake is 1 in 10, a SS of 2 means probability of collapse is 1 in 100, and similarly a SS of 3 reflects probability of 1 in 1000. Based on SS, researchers have correlated it with damage grades of EMS to classify buildings based on vulnerability. The interpretation of damage grade (DG) for the SS depends on 5 damage grades systems for both masonry and reinforced concrete buildings as shown in Table 2. Different relationships have been used by different researchers to correlate SS values with DG $[39,40]$. Some researchers related SS greater than 3 to DG 1 while some have taken SS greater than 2.5 to fall in DG 1. In the current study, the relationship developed by Nanda and Majhi [40] for India is being adopted due to similar construction practices being observed in Pakistan. Different damage grades with their corresponding damage level and description for both masonry and reinforced concrete structures are explained in European Macro Seismic Scale [41]. Score greater than 2.5 and lying between 2.0 and 2.5 gives the probability of DG 1 and DG 2, respectively, which is low to moderate damage. For these two damage grades, minor repairing is required, while detailed evaluation is not necessary. SS less than 2 is associated with damage grades 3 to 5 which reflects heavy structural damage. Generally, the SS less than 0.7 indicates high vulnerability, which means detailed evaluation and retrofitting of the building is required.

To compute SS for each building, appropriate RVS sheet is selected based on the seismicity of that area. To do that, values of short-period spectral acceleration $\left(S_{s}\right)$ and long-period spectral acceleration $\left(\mathrm{S}_{1}\right)$ are computed for MCE level earthquakes. Values of $S_{s}$ and $S_{1}$ for Sam Ranizai and Swat Ranizai of Malakand are selected from the Seismic Hazard Analysis and Zonation for Pakistan, Azad Jammu, and Kashmir carried out by PMD [23]. Values for an MCE level earthquake are not present and are therefore obtained from the DBE values by multiplying them by a factor of 1.5, which is usually used. Based on the values of $\mathrm{S}_{\mathrm{s}}$ and $\mathrm{S}_{1}$, Sam Ranizai and Swat Ranizai lie in moderately high and high seismicity regions, respectively, according to FEMA P-154 [42]. Latitude and longitude of each building are recorded on RVS sheet, and based on shear wave velocity data, soil type is picked from Table 3 . Shear wave velocity data are taken from the United States Geological Survey database [43].

The RVS method is a simple and relatively quick procedure to pinpoint highly vulnerable buildings. However, its results are not correct at individual level but are significant at the scale of set of buildings. This method can be applied

Table 3 Soil types [42]

\begin{tabular}{lll}
\hline Soil type & Name & Shear wave velocity $V_{\text {s30 }}(\mathrm{Ft} / \mathrm{s})$ \\
\hline Hard rock & Type $A$ & $>5000$ \\
Soft rock & Type B & $2500<V_{\mathrm{s} 30} \leq 5000$ \\
Dense soil & Type C & $1200<V_{\mathrm{s} 30} \leq 2500$ \\
Stiff soil & Type $\mathrm{D}$ & $600<V_{\mathrm{s} 30} \leq 1200$ \\
Soft soil & Type E & $\leq 600$ \\
Poor soil & Type $\mathrm{F}$ & Requires specific evaluation \\
\hline
\end{tabular}

Table 2 Structural scores with corresponding damage grades [40]

\begin{tabular}{ll}
\hline RVS score & Damage potential \\
\hline SS $\leq 0.3$ & High probability of Grade 5 damage; very high probability of Grade 4 damage \\
$0.3<$ SS $\leq 0.7$ & High probability of Grade 4 damage; very high probability of Grade 3 damage \\
$0.7<$ SS $\leq 2.0$ & High probability of Grade 3 damage; very high probability of Grade 2 damage \\
$2.0<$ SS $\leq 2.5$ & High probability of Grade 2 damage; very high probability of Grade 1 damage \\
SS $>2.5$ & Probability of Grade 1 damage \\
\hline
\end{tabular}


to a set of buildings in order to highlight highly vulnerable buildings requiring detailed evaluation and retrofitting.

\subsection{Indicators of RVS method affecting the seismic behavior of buildings}

Apart from the expected intensity of seismic hazard, seismic performance of buildings depends upon the lateral load resisting system, material type, plan symmetry, vertical regularity, soil condition, construction quality, cracks, wall openings, etc. Non-structural elements vulnerability can be observed during the RVS; however, it cannot be quantified in the calculation of the final structural score as it depends on a myriad number of factors. However, factors considered in RVS procedure of FEMA P-154 are explained briefly below.

\subsubsection{Building type}

Seismic performance of a building primarily depends on its lateral load resisting type [44]. Buildings constructed from non-engineered and semi-engineered materials without any engineering input are highly vulnerable; however, buildings constructed from engineered materials also become vulnerable if met with the severe plan and vertical irregularities. Based on construction types and building materials, seventeen types of buildings are selected in FEMA P-154 [42]. Construction types include both properly designed constructions according to codes and regulations and non-engineered construction without following specifications. Unconfined masonry structures are assigned low basic scores because of their high vulnerability.

\subsubsection{Building height}

The height of a building can influence its seismic performance. Generally speaking, low-hight buildings are considered seismically less vulnerable [45]. Two types of height ranges are considered in this latest RVS procedure of FEMA: 1-3 stories and more than 3 stories; however, the modification score for building height is applicable only if a building is located on the soil type E. Building height does not greatly influence seismic performance, and therefore its score modifier is applicable only to soft soil (type E).

\subsubsection{Plan irregularity}

Buildings having a symmetrical plan are considered to exhibit good seismic performance in earthquakes. Buildings having plan irregularity like $\mathrm{L}, \mathrm{U}$ and + shape sustained significant damages in past earthquakes. Irregularity in the plan adversely affects the seismic performance of a building [46]. Due to an adverse effect of plan irregularity on the seismic behavior of a building, its corresponding score modifier for all types of buildings is negative. Plan irregularity has a less adverse effect on seismic performance as compared to vertical irregularity and therefore has a less score modifier than vertical irregularity for all types of buildings.

\subsubsection{Vertical irregularity}

A building is termed as vertically irregular if there is any physical discontinuity in vertical configuration or lateral load resisting system. In commercial buildings, people use the ground floor for car parking with no masonry infill walls, thus producing a soft story effect. Same is the case in residential buildings, where people use the ground story for commercial purposes like shops. Vertical irregularity in 2- and 3-story buildings can exist due to vertical setbacks, short column effect, and soft story effect on the ground floor. Due to adverse effects of vertical irregularity on seismic performance of buildings $[47,48]$, its corresponding score modifier for all types of buildings is negative. This modifier due to its significant adverse effect has assigned the highest negative score modifier in the calculation of the final structural score.

\subsubsection{Building construction quality}

Buildings having poor construction quality and workmanship exhibit poor seismic performance [3]. Although judgment cannot be made about a building's construction quality, a trained observer can make an inference about the original quality of construction by looking at the present condition of the building like cracks, damage, spalling of concrete, ground settlement, dampness, etc. This factor was included in FEMA 154 [49] but is removed in FEMA P-154 [42].

\subsubsection{Soil condition}

Underlying soil conditions in a particular area can amplify or dissipate the energy of seismic waves and can greatly influence the amplitude and duration of the shaking, affecting the seismic performance of structures significantly [50]. Depending on soil type, its corresponding score modifier may be negative or positive. Soil types A and B do not amplify seismic wave's energy significantly and have therefore assigned a positive score modifier in the calculation of the final structural score. 


\subsubsection{Post-benchmark}

The year in which building code adoption in an area is made mandatory by authorities is termed as the benchmark year. This modifier is applicable to buildings constructed after the benchmark year. However, in the case study area, the building code adoption is still not made mandatory by concerned authorities, so this modifier is applicable only if the owners have adopted the building code. Code compliant structure exhibits good performance in earthquakes [51] and therefore has positive score modifiers. Buildings designed according to building codes are less vulnerable; therefore, the post-benchmark modifier is assigned a high positive score modifier.

\subsubsection{Pre-code}

In developing countries, there are still buildings which were constructed prior to the initial adoption and enforcement of seismic codes. Buildings constructed prior to seismic codes are expected to exhibit poor performance in earthquakes and therefore are highly vulnerable [52]. If a building is constructed prior to the initial adoption of building code for that particular FEMA building type, this modifier is applicable. This score modifier for all types of buildings is negative. A negative significant score is assigned to this modifier in the calculation of the final structural score.

\section{Data collection and analysis}

Conducting the RVS program successfully requires every aspect like data collection form selection, soil type identification, etc., to be reviewed during the pre-field planning stage. The first step was to define the goals and objectives. Selection of the data collection form for respective regions based on seismicity is discussed earlier. The next step was to select team members for screening and to train them. For this purpose, three postgraduate students of Structural Engineering were selected and trained by experts about how to carry out a field survey. Pre-field data selected by the team were reviewed and verified by experts. Soil type was identified at the start of the survey as it's not possible to identify it visually in the field and was documented on the respective RVS data collection forms. Data collection was performed by the first author himself along with the team members. As it is not possible to perform RVS of the entire building stock of an area as it is time-consuming, cumbersome, and costly, a total of 400 residential, 40 schools, and 40 CB were surveyed. Map showing spatial distribution of schools in both subdivisions is shown in Fig. 2. The sample size was calculated based on total households $(91,414)$ [35] using Yamane formula [53]. The sample size was further distributed between Sam Ranizai and Swat Ranizai proportionally based on household numbers in each subdivision. A final sample size of 170 for Sam Ranizai and 230 for Swat Ranizai for residential buildings was selected. Survey work was carried out for a period of 6 months from September 2018 to February 2019 in sub-districts of Malakand covering all smallest units of administration (Union Council). Buildings were reviewed from the street-based sidewalk survey (from all four sides when possible) and internally as well. Each survey lasted for an average of 45-60 min. Quality of data collection was checked at the end of every day, and difficulties encountered during the survey were discussed and handled on. Few of the inspected buildings were damaged in recent earthquakes. The observed seismic behavior of these buildings is discussed in detail subsequently. In the end, the digital database was compiled for performing analysis and to keep the record. Grounded along with the final SS values, outcomes were generated.

\subsection{Description of observed case study buildings}

Due to poor economic conditions of the residents, houses made of mud bricks, mud and straw are still in use. Adobe buildings have low earthquake resistance and have suffered severe damages in the past from earthquakes [52]. Adobe buildings are still present in Malakand, but are less in number as compared to other types of buildings which is a good sign as people nowadays prefer houses made of burnt bricks and engineering materials as compared to other locally available materials like block and stones believing that buildings made of bricks and cement performs well in earthquakes.

Masonry structures are not only common in Pakistan, but all over the world. Both confined brick masonry (CM), as shown in Fig. S1, and unconfined brick masonry (UCM) buildings are abundant in numbers than other types of buildings. Building heights generally varied from one to three stories. Most of the masonry buildings have reinforced concrete slab as floor and roof material; however, slabs are not properly tied to the walls in the case of UCM buildings. One common and important observation among all masonry buildings was English bond, which is heartening to see as this bond is stronger than other bonds. Brick masonry walls have been found to be 9 inches thick usually. Properties of materials like the initial absorption rate of bricks and compressive strength of mortar are poor and are different from those in other parts of the world [54]. Brick masonry buildings constructed with mud or poor cement mortar are highly vulnerable [55].

Block structures are also in use in Malakand. Both confined block masonry (CBM) and unconfined block masonry 


\section{(a)}

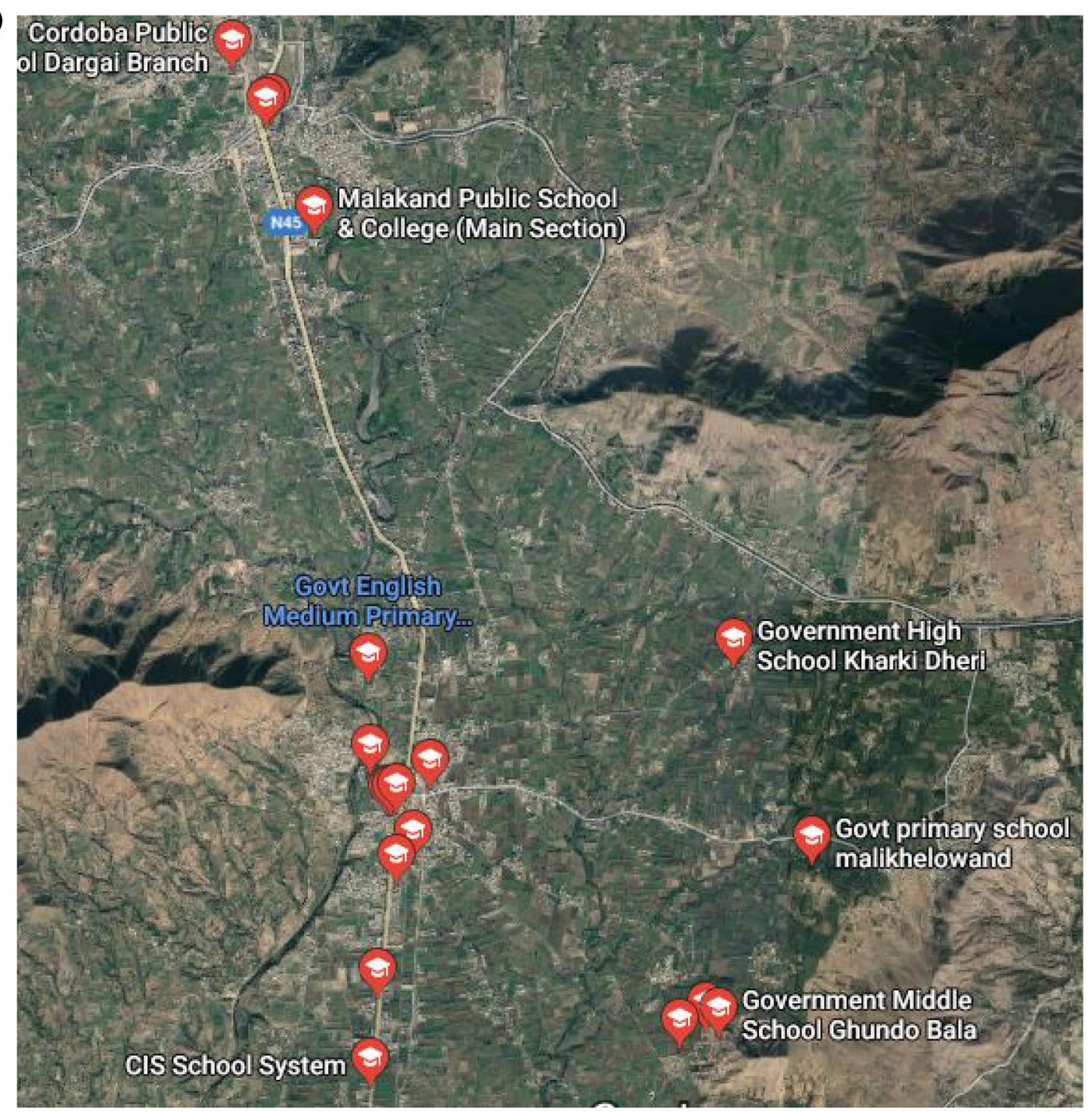

(b)

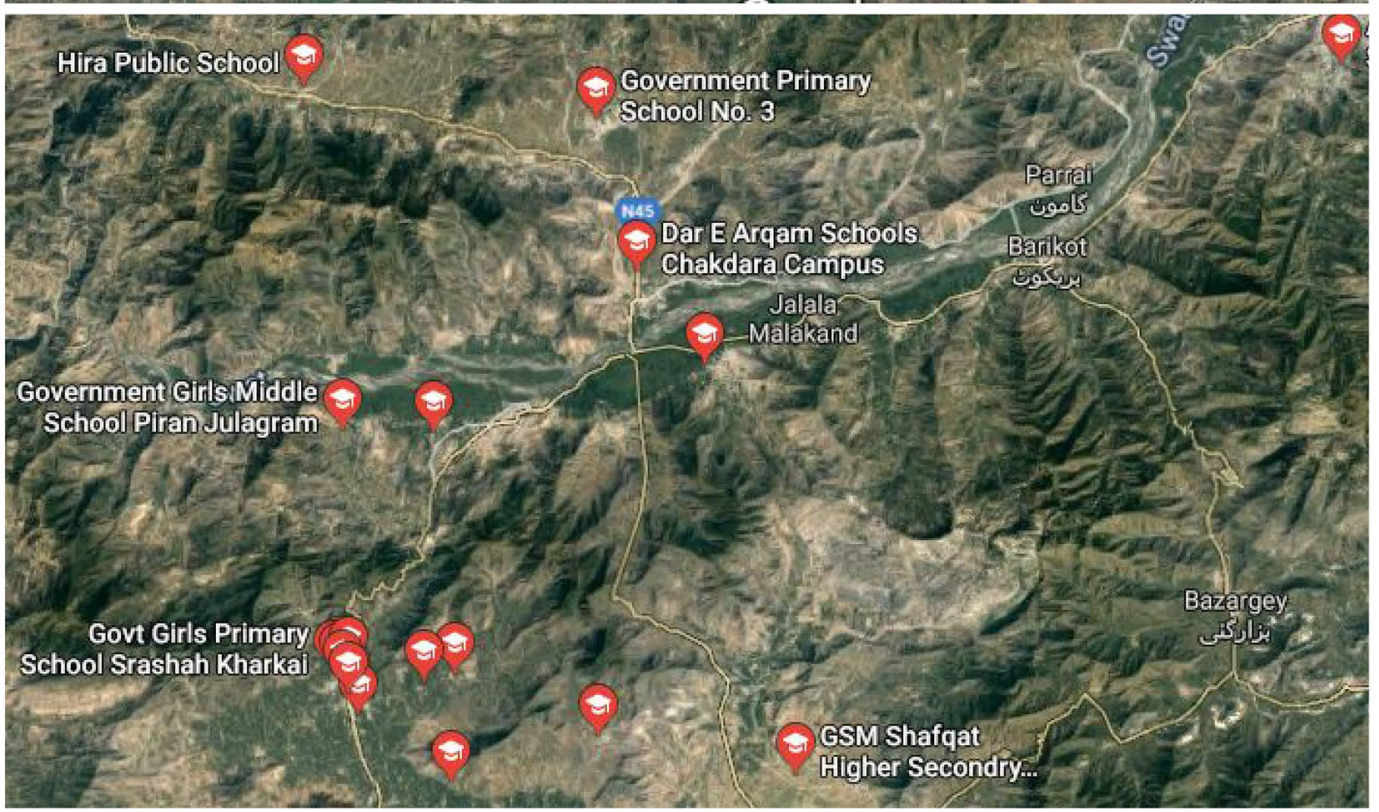

Fig. 2 Spatial distribution of schools a Sam Ranizai b Swat Ranizai 
(UCBM) buildings are available in Malakand. Seismic performance of UCBM is poor, and due to lack of a proper lateral load resisting system, the entire structure becomes highly susceptible to collapse as observed in the Kashmir earthquake [3]. Bond in block walls is stretcher bond, and thickness of walls is generally 6 inches.

Stone masonry buildings are abundantly constructed in KPK and Punjab [56]. Confined stone masonry (CSM) and unconfined stone masonry (UCSM) buildings, as shown in Figs. S2 and S3, are constructed in the past as well as in the present in Malakand. These buildings are constructed with mud, lime, or cement as a mortar or without mortar. As it is not properly designed to resist earthquakes, it has performed poorly in past earthquakes and some even collapsed. Buildings made of rubble stones are highly vulnerable ,and it is estimated that 40 percent of building stock may collapse in the Himalayan region if subjected to an earthquake of magnitude 7 or higher [57].

No structure made of wood or steel was surveyed in the case study area as these buildings are not common. People believe that wood is not durable, and steel is not economical to construct houses. However, people use wood as roof material as it is cheaper compared to other roofing material like the reinforced cement concrete, angle iron with burnt bricks, etc. CM, UCM, CBM, UCBM, CSM, and UCSM buildings are common types of buildings in the case study area. Other types of buildings like reinforced concrete moment-resisting frame and concrete frame buildings with unreinforced masonry infill walls were also surveyed as shown in Fig. S4. All residential buildings surveyed were not constructed according to BCP SP-07 [36]. Different types of buildings surveyed in both Sam Ranizai and Swat Ranizai are shown in Table 4.

The life span of residential buildings is short due to the poor construction quality and maintenance level. Most of the case study buildings are aging less than 20 years. Most of the residential buildings in Sam Ranizai and Swat Ranizai are single or double story. As compared to Sam Ranizai, buildings greater than one story are dominant in Swat Ranizai. A diagram depicting the height and percentage of different type buildings in both Sam Ranizai and Swat Ranizai is shown in Fig. 3.
Table 4 Number of different types of buildings surveyed in Sam Ranizai and Swat Ranizai

Fig. 3 Height of different building types in Sam Ranizai and Swat Ranizai

\begin{tabular}{|c|c|c|c|c|c|c|}
\hline \multirow[t]{2}{*}{ Types of buildings } & \multicolumn{3}{|l|}{ Sam Ranizai } & \multicolumn{3}{|l|}{ Swat Ranizai } \\
\hline & Residential (\%) & School (\%) & $\begin{array}{l}\text { Com- } \\
\text { mercial } \\
(\%)\end{array}$ & Residential (\%) & School (\%) & $\begin{array}{l}\text { Com- } \\
\text { mercial } \\
(\%)\end{array}$ \\
\hline UM & 17.65 & 20 & 10 & 20.43 & 20 & 15 \\
\hline CM & 30 & 25 & 25 & 23.48 & 30 & 20 \\
\hline UCBM & 11.18 & 5 & 0 & 9.13 & 0 & 5 \\
\hline CBM & 14.71 & 10 & 10 & 14.35 & 5 & 10 \\
\hline UCSM & 6.47 & 0 & 0 & 8.26 & 15 & 0 \\
\hline CSM & 5.29 & 0 & 0 & 4.78 & 0 & 0 \\
\hline Others & 14.70 & 40 & 55 & 19.57 & 30 & 50 \\
\hline
\end{tabular}

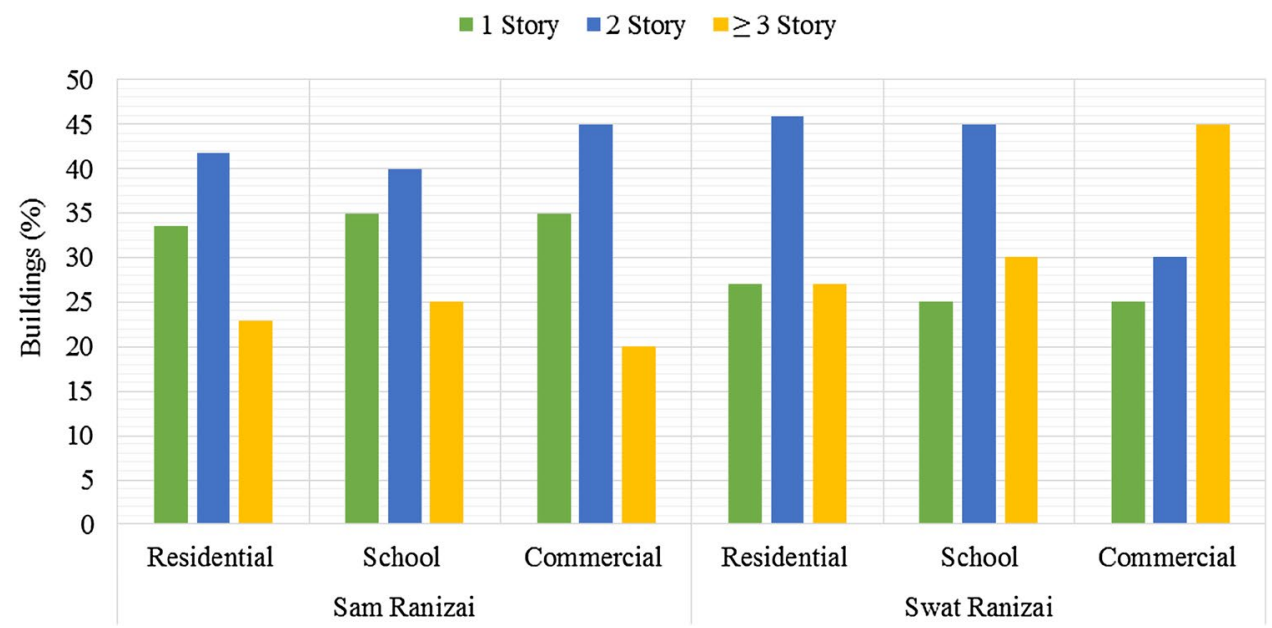




\subsection{Observed seismic behavior of buildings in past earthquakes}

Most of the buildings in district Malakand have suffered from minor to severe damages in past earthquakes. During the survey, people discussed structural and non-structural damages experienced by their buildings in the 2005 Kashmir earthquake and in more recent earthquakes. Some of the common failures observed in damaged buildings include severe vertical cracks in the walls as shown in Fig. S5, horizontal cracks at the joint between roof and wall as shown in Fig. S6, severe vertical crack at the joint between two walls as shown in Fig. S7, cracks in flexible floors due to lack of rigid diaphragm action as shown in Fig. S8, and diagonal shear crack in masonry walls as shown in Fig. S9. Poor construction quality and workmanship, use of poorquality materials, improper detailing, severe irregularities, lack of vertical confining elements at the end of load-bearing walls, and insufficient diaphragm stiffness were also observed, and these factors significantly affected the seismic performance of buildings as observed in the past [3]. Diagonal shear cracks in masonry walls do not reduce their gravity load-carrying capacity unless the cracks are severe or there exists some out-of-plane movement. A horizontal crack at the joint between slab and wall in unreinforced masonry buildings shows slides of the roof as shown in Fig. S6. If horizontal cracks appear at the base of the walls, it shows the horizontal shear failure of walls. One important failure observed in existing stone masonry buildings was vertical cracks at the joints between two walls as they were not properly tied, which may lead to the collapse of wall corners as observed in the past [58]. These types of failures in buildings were observed in 2005 Kashmir [3] and 2015 Hindu Kush earthquake [59]. Most of the damaged structures in the case study area were found to be unreinforced masonry.

Performance of stone masonry buildings in previous earthquakes is found to be poor due to poor interlocking, improper size and shape of stones. Unreinforced stone masonry buildings were damaged due to lack of structural integrity caused by improper bonding of cross walls. Unreinforced masonry buildings exhibit brittle failure, sliding off the roof, and diagonal shear cracks in the walls [60], and these types of failures were observed in 2015 Hindu Kush earthquake as well [59]. Confined masonry structures, as opposed to unconfined masonry structures, are found to exhibit good seismic performance and high energy dissipation capacity [60].

Few of the surveyed school buildings in both Sam Ranizai and Swat Ranizai are unconfined brick or stone masonry and are aged more than 20 years. Retrofitting of these buildings can contribute to risk reduction [61]. The seismic capacity of buildings built from locally available materials without any engineering input needs to be improved to reduce probable losses in future earthquakes [62]. Masonry structures are most dominant in Malakand and need to be retrofitted. The seismic capacity of different masonry structures can be improved by economical ways of retrofitting $[62,63]$. Remedial measures for different types of irregularities in buildings need to be taken to minimize losses in the future [38].

\section{Results and discussion}

\subsection{Structural damage assessment of buildings}

Based on RVS sheets, SS is calculated for each type of building. In the case of a negative or less than minimum SS recommended by FEMA P-154, minimum SS formulated on the RVS sheet is encircled. Results revealed that $41 \%$ of residential buildings in Sam Ranizai and $40 \%$ of residential buildings in Swat Ranizai scored between 0.7 and 2 and lie in DG 3 which is a moderate DG. Most of the buildings having age 20 or more are unconfined masonry (brick, block, or stone) and scored less than 0.7 , which warrants a detailed evaluation and retrofitting. None of the residential buildings in Swat Ranizai lie in DG 1 which is disheartening to see as this subdivision is at high seismic hazard. Buildings in Sam Ranizai without any plan and vertical irregularity and lying on a soil type A or B scored more than 2.5 due to positive score modifier of these soil types and lie in DG 1. Results revealed that $39 \%$ of buildings in Sam Ranizai and 43\% in Swat Ranizai lie in DG 4 and DG 5, which are high damage grades, and these buildings can experience major structural damage in future earthquakes which may result in a large number of casualties. The total number of residential buildings in Sam Ranizai and Swat Ranizai with their corresponding damage grades is shown in Fig. 5.

School buildings are an important part of the built environment which in daytime accommodates a large number of children; particular care needs to be given to schools as school kids compared to adults are highly vulnerable. Private schools are more in number than government schools in district Malakand. Government schools are given particular care nowadays and are constructed in accordance with building regulations, and most of them are found to be less vulnerable as compared to private schools. Most of the private schools are semi-engineered and may sustain heavy structural damage against future earthquakes. Few of government schools aged more than 20 years are non-engineered and are constructed of unconfined brick or stone masonry and are highly vulnerable. Most of the government schools constructed nowadays in Malakand are reinforced concrete moment-resisting frames and are 
2 or 3 stories high. Most of the private schools surveyed are confined or unconfined masonry. A total of 40 schools were inspected: 20 from Sam Ranizai and 20 from Swat Ranizai, including 10 government schools and 10 private schools. Results disclosed that private schools in Malakand are not constructed to resist earthquakes and most of them lie in high damage grades. Out of surveyed, $3 \mathrm{gov}$ ernment schools and 5 private schools in Sam Ranizai and 4 government schools and 6 private schools in Swat Ranizai lie in high DG 4 and DG 5 and need detailed evaluation and retrofitting. None of the surveyed private schools lies in DG 1 and DG 2 which is alarming. High vulnerability of buildings can be attributed due to lack of policy implementation and less awareness among the private sector. To reduce the vulnerability of building stock in the future, enforcement of building codes and earthquakeresistant design of buildings should be the first priority of concerned authorities, especially in the case of schools. The number of schools with their corresponding damage grades is shown in Fig. 4.

Vulnerability assessment of school buildings is required in order to prioritize highly vulnerable schools and take necessary steps to reduce overall seismic risk, as a number of school buildings were damaged and collapsed in the 2005 Kashmir earthquake, resulting in huge losses of lives and assets. Schools need to be given special care and should be operational immediately after an earthquake as it plays a vital role in helping communities to cope with earthquakes [64]. Hospitals are also key buildings in the built environment and should be functional after a disaster to provide facilities to the community. Future works focused on the seismic vulnerability of hospital buildings need to be carried out.

Most of the commercial buildings in Malakand are non-engineered. Plan irregularity, vertical setbacks, short column, soft story, split level irregularity, pounding, etc., are some common deficiencies observed in commercial buildings. The most common type of plan irregularity observed in commercial buildings is $U$ shaped. Out of 20 commercial buildings surveyed in Sam Ranizai and Swat Ranizai, 7 in Sam Ranizai and 9 in Swat Ranizai scored less than 0.7 and are highly vulnerable. Unconfined masonry, confined masonry, and reinforced concrete momentresisting frame buildings are the most common type of commercial buildings in the case study area. Few of the case study buildings are constructed using engineering expertise (as its owners will whether to adopt building codes or not) and all lie in DG 1. Results disclosed that most of the commercial buildings are seismically vulnerable and lie in DG 4 and DG 5 as shown in Fig. 5, which may lead to huge socioeconomic losses in the future. High vulnerability of commercial buildings is due to less awareness among people. It was observed during the survey that owners believe design their buildings to resist earthquakes will cost them more.

Diagram depicting damage grades with the corresponding percentage of residential buildings, school buildings, and commercial buildings is shown in Fig. 5 . Results disclosed that more than $50 \%$ of residential buildings, school buildings, and commercial buildings lie in DG 3-5 which is depressing to see as these buildings will sustain heavy structural and non-structural damages in future earthquakes. Comparative vulnerability assessment of residential buildings, school buildings, and commercial buildings show that buildings falling in DG 4 and DG 5 are more in Swat Ranizai as compared to Sam Ranizai, as this subdivision is at high earthquake hazard. Results revealed that almost half of different building use-types will sustain high damage in the future. High vulnerability of buildings is due to less awareness among community members about earthquake risk and how to cope with it, development and lack of policy implementation by concerned authorities, and people fatalistic stance toward future earthquakes.
Fig. 4 Damage grades of school buildings in Sam Ranizai and Swat Ranizai

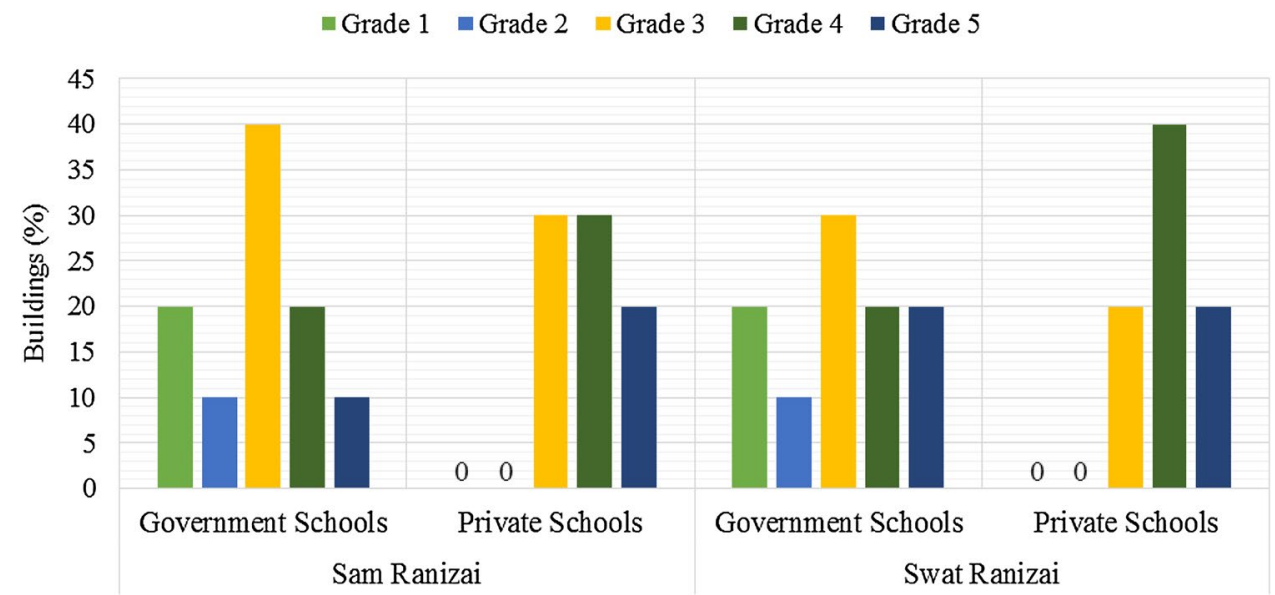


Fig. 5 Buildings with corresponding damage grades

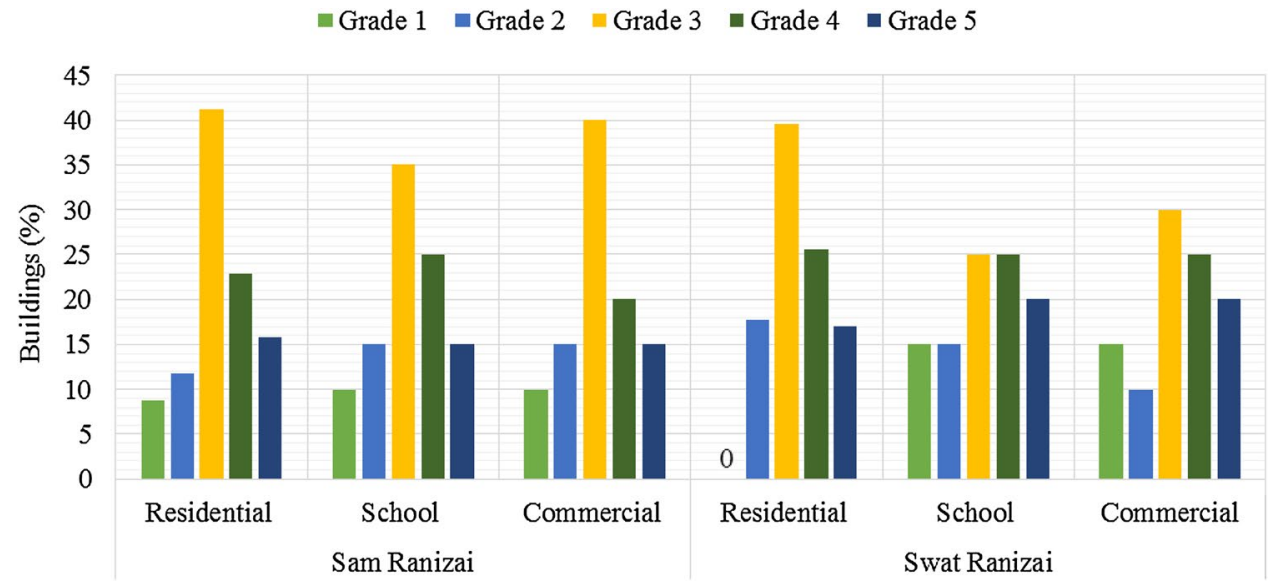

Descriptive analysis of all types of buildings disclosed that two-third of UCSM buildings in both Sam Ranizai and Swat Ranizai lie in high DG 4 and 5 and these buildings will be the most damaged ones in future earthquakes, and it was the most damaged ones in recent earthquakes as discussed earlier. Half of the UCBM buildings lie in DG 4 and 5. Different types of lateral load resisting systems for each type of building with the corresponding percent of buildings falling in DG 4 and 5 are shown in Table 5. Timely rehabilitation and retrofitting of highly vulnerable UCSM and UCBM buildings are required in order to minimize losses in the future.

\subsection{Future economic losses}

According to the results of the simplified RVS procedure, the buildings in DG5 will probably sustain heavy damage in future earthquakes. In the present study, these buildings are taken as demanding reconstruction and the entire contents of these buildings are supposed to be lost in future earthquakes. Buildings falling in the DG 4 category are, however, taken as being capable of reestablishment. The reestablishment cost of buildings falling in DG 4 is considered $20 \%$ of their replacement cost [65].

Due to future earthquakes, losses likely to be prompted to the built environment are measured as the cost of reconstruction of buildings falling in DG 5 along with the cost of repair of buildings falling in DG 4 . The total cost of expected losses is calculated according to market rates considering the total area of constructed buildings likely to be damaged. Value of the contents in the buildings is assessed as well, as a function of reconstruction cost and building use. The economic worth of the contents likely to be lost is taken to be $50 \%, 25 \%, 200 \%$, and $100 \%$ of the cost of reconstruction of the structures for residential, school, commercial, and mixed (residential and commercial) buildings, respectively [65].
Table 5 Different types of buildings with corresponding percent of buildings falling in category 4 and 5 damage

\begin{tabular}{|c|c|c|c|c|c|c|c|c|c|c|}
\hline \multirow[t]{2}{*}{ Subdivisions } & \multirow[t]{2}{*}{ Type of building } & \multicolumn{3}{|c|}{ Residential (\%) } & \multicolumn{3}{|c|}{ School (\%) } & \multicolumn{3}{|c|}{ Commercial (\%) } \\
\hline & & Total & DG 4 & DG 5 & Total & DG 4 & DG 5 & Total & DG 4 & DG 5 \\
\hline \multirow[t]{7}{*}{ Sam Ranizai } & UM & 17.65 & 3.53 & 2.35 & 20 & 0 & 0 & 10 & 5 & 0 \\
\hline & $\mathrm{CM}$ & 30.00 & 4.12 & 2.94 & 25 & 0 & 0 & 25 & 10 & 5 \\
\hline & UCBM & 11.18 & 3.52 & 2.35 & 5 & 5 & 0 & 0 & 0 & 0 \\
\hline & CBM & 14.71 & 2.94 & 2.35 & 10 & 5 & 0 & 10 & 0 & 0 \\
\hline & UCSM & 6.47 & 2.94 & 1.18 & 0 & 0 & 0 & 0 & 0 & 0 \\
\hline & CSM & 5.30 & 1.76 & 1.18 & 0 & 0 & 0 & 0 & 0 & 0 \\
\hline & Others & 14.71 & 4.12 & 3.53 & 40 & 15 & 15 & 55 & 5 & 10 \\
\hline \multirow[t]{7}{*}{ Swat Ranizai } & UM & 20.44 & 4.35 & 2.61 & 20 & 10 & 0 & 15 & 10 & 0 \\
\hline & $\mathrm{CM}$ & 23.48 & 3.91 & 2.17 & 30 & 5 & 0 & 20 & 0 & 10 \\
\hline & UCBM & 9.13 & 3.04 & 2.17 & 0 & 0 & 0 & 5 & 0 & 0 \\
\hline & CBM & 14.35 & 2.61 & 2.61 & 5 & 0 & 0 & 10 & 0 & 5 \\
\hline & UCSM & 8.26 & 3.48 & 2.17 & 15 & 10 & 5 & 0 & 0 & 0 \\
\hline & CSM & 4.79 & 1.74 & 0.87 & 0 & 0 & 0 & 0 & 0 & 0 \\
\hline & Others & 19.57 & 6.52 & 4.35 & 30 & 0 & 15 & 50 & 15 & 5 \\
\hline
\end{tabular}


The total developed area of surveyed residential buildings falling in DG 4 and 5 is calculated to be $25,700 \mathrm{~m}^{2}$ and $22,126 \mathrm{~m}^{2}$, respectively. At the market rate of the US\$250 per $\mathrm{m}^{2}$, the total reconstruction cost of residential buildings falling in DG 5 is estimated to be US\$ 5.53 million. The restoration cost of residential buildings falling in DG 4 is estimated to be the US\$ 1.285 million. The total built-up area of commercial buildings surveyed falling in DG 5 is $4044 \mathrm{~m}^{2}$ and falling in DG 4 is $4700 \mathrm{~m}^{2}$. The reconstruction and restoration costs of commercial buildings falling in DG 5 and DG 4 are estimated to be the US\$ 1.011 and US\$ 0.235 million, respectively. The total built-up area of school buildings is calculated to be $1800 \mathrm{~m}^{2}$ and $2500 \mathrm{~m}^{2}$ of buildings falling in DG 5 and DG 4, respectively. The total replacement cost of surveyed school buildings falling in DG 5 is estimated at around US\$ 0.45 million, and the restoration cost of school buildings falling in DG 4 is estimated around US\$ 0.125 million. The total economic value of the contents likely to be lost in residential, commercial, and school buildings falling in DG 5 is estimated around US\$2.765, US\$2.022 and US\$ 0.1125 million, respectively. Thus, total economic losses to incur to the surveyed buildings only falling in DG 4 and 5 in Sam Ranizai and Swat Ranizai are estimated to US\$ 13.5355 million.

\section{Conclusions}

In this study, vulnerability assessment of different use-type buildings were carried out using the latest FEMA methodology in an earthquake-prone Malakand district of KPK, where no such studies were done in the past, despite being declared as a high-earthquake-risk area by NDMA of Pakistan. Future possible damages are depicted as a function of damage grades of European Macro Seismic Scale. Structural damage assessment and seismogenic losses in economic terms disclose that Malakand may suffer enormously in future earthquakes. Replacement of highly vulnerable buildings is not possible; however, there is a need to undertake massive awareness drive for risk communication and for bringing forth acceptability of appropriate seismic safety measure among the masses. People routinely invest in the maintenance of their buildings and on the better interior and exterior decoration; however, by forewarning them about the situation many would dovetail maintenance with retrofitting.

Vulnerability assessment of the buildings followed by a restoration and rehabilitation program can minimize the adverse impacts of earthquakes. The current study measures the seismic vulnerability of buildings of different usetypes in a high seismic area of Malakand district, Pakistan, using a rapid visual screening method of FEMA. It was observed during the survey that the recent earthquakes caused significant damages to the unconfined masonry buildings with stone masonry experiencing maximum damages followed by block and brick masonry, respectively. Reinforced concrete buildings were found to be semi-engineered, and severe vertical irregularities like the soft story, short column, heavy overhangs, and vertical setbacks were observed. The most common type of plan irregularity observed in residential and commercial buildings was $L$ and $U$ shape, respectively. Damage grades of the buildings obtained from structural scores showed that almost half of all building types either needs rehabilitation or needs to be replaced entirely. School buildings were found more vulnerable than residential buildings. Results further reveal a lack of awareness/poor policy implementation in the private sector as the private school buildings were found to be considerably more vulnerable compared to their government counterparts. Total economic losses to the surveyed buildings, which make up less than $1 \%$ of the total building stock, are estimated to be around US\$ 13.5 million. The study recommends that the concerned authorities must create awareness among people by various campaigns regarding safe construction practices, along with the strict implementation of building regulations in the area. Furthermore, timely rehabilitation of highly vulnerable buildings must be carried out which can lead to an effective earthquake risk reduction.

This study has implemented a methodology developed in the USA that is used worldwide nowadays. This RVS methodology is simple yet effective and can be adopted in any country for vulnerability assessment. Seismic vulnerability assessment studies help Disaster Managers, Urban Planners, concerned authorities, etc., to design effective risk reduction policies in the future.

\section{Compliance with ethical standards}

Conflict of interest On behalf of all authors, the corresponding author states that there is no conflict of interest.

\section{References}

1. Gaillard JC, Texier P (2010) Religions, natural hazards, and disasters: an introduction. Religion 40(2):81-84. https://doi. org/10.1016/j.religion.2009.12.001

2. Masozera M, Bailey M, Kerchner C (2007) Distribution of impacts of natural disasters across income groups: a case study of New Orleans. Ecol Econ 63(2):299-306. https://doi.org/10.1016/j. ecolecon.2006.06.013

3. Naseer A, Khan AN, Hussain Z, Ali Q (2010) Observed seismic behavior of buildings in Northern Pakistan during the 2005 Kashmir earthquake. Earthq Spectra 26(2):425-449. https://doi. org/10.1193/1.3383119

4. Murnane R, Simpson A, Jongman B (2016) Understanding risk: what makes a risk assessment successful? Int J Disast Resil 
Built Environ 7(2):186-200. https://doi.org/10.1108/IJDRB E-06-2015-0033

5. Rafi Z, Lindholm C, Bungum H, Laghari A, Ahmed N (2012) Probabilistic seismic hazard of Pakistan, Azad-Jammu and Kashmir. Nat Hazards 61(3):1317-1354. https://doi.org/10.1007/s1106 9-011-9984-4

6. Sinha R, Goyal A (2004) A national policy for seismic vulnerability assessment of buildings and procedure for rapid visual screening of buildings for potential seismic vulnerability. Report to Disaster Management Division, Ministry of Home Affairs, Government of India, Hindistan

7. Aghataher R, Delavar M, Nami M, Samnay N (2008) A fuzzy-AHP decision support system for evaluation of cities vulnerability against earthquakes. World Appl Sci J 3(1):66-72

8. Calvi GM, Pinho R, Magenes G, Bommer JJ, Restrepo-Vélez LF, Crowley H (2006) Development of seismic vulnerability assessment methodologies over the past 30 years. ISET J Earthq Technol 43(3):75-104

9. Guéguen P, Michel C, LeCorre L (2007) A simplified approach for vulnerability assessment in moderate-to-low seismic hazard regions: application to Grenoble (France). Bull Earthq Eng 5(3):467-490. https://doi.org/10.1007/s10518-007-9036-3

10. Al-Nimry H, Resheidat M, Qeran S (2015) Rapid assessment for seismic vulnerability of low and medium rise infilled RC frame buildings. Earthq Eng Eng Vib 14(2):275-293. https://doi. org/10.1007/s11803-015-0023-4

11. El-Kholy SA, El-Assaly MS, Maher M (2012) Seismic vulnerability assessment of existing multi-story reinforced concrete buildings in Egypt. Arab J Sci Eng 37(2):341-355. https://doi.org/10.1007/ s13369-012-0170-0

12. Joshi GC, Ghildiyal S, Rautela P (2019) Seismic vulnerability of lifeline buildings in Himalayan province of Uttarakhand in India. Int J Disast Risk Reduct. https://doi.org/10.1016/j.ijdrr .2019.101168

13. Inel M, Senel SM, Toprak S, Manav Y (2008) Seismic risk assessment of buildings in urban areas: a case study for Denizli, Turkey. Nat Hazards 46(3):265-285. https://doi.org/10.1007/s1106 9-007-9187-1

14. Baba Hamed FZ, Rahal DD, Rahal F (2013) Seismic risk assessment of Algerian buildings in urban area. J Civil Eng Manag 19(3):348-363. https://doi.org/10.3846/13923730.2012.744772

15. Rainer J, Allen D, Jablonski A (1992) Manual for screening of buildings for seismic investigation. National Research Council Canada

16. Jain SK, Mitra K, Kumar M, Shah M (2010) A proposed rapid visual screening procedure for seismic evaluation of RC-frame buildings in India. Earthq Spectra 26(3):709-729. https://doi. org/10.1193/1.3456711

17. Perrone D, Aiello MA, Pecce M, Rossi F (2015) Rapid visual screening for seismic evaluation of RC hospital buildings. In: Structures. Elsevier, pp 57-70. https://doi.org/10.1016/j.istru c.2015.03.002

18. Sucuoğlu H, Yazgan U, Yakut A (2007) A screening procedure for seismic risk assessment in urban building stocks. Earthq Spectra 23(2):441-458. https://doi.org/10.1193/1.2720931

19. Yadollahi M, Adnan A, Zin RM (2012) Seismic vulnerability functional method for rapid visual screening of existing buildings. Arch Civil Eng 58(3):363-377. https://doi.org/10.2478/v.10169 -012-0020-1

20. Engineering NZSfE (2014) Assessment and improvement of the structural performance of buildings in earthquakes: prioritisation, initial evaluation, detailed assessment, improvement measures: recommendations of a NZSEE Study Group on Earthquake Risk Buildings. New Zealand Society for Earthquake Engineering

21. Khan S, Qureshi MI, Rana IA, Maqsoom A (2019) An empirical relationship between seismic risk perception and physical vulnerability: a case study of Malakand, Pakistan. Int J Disast Risk Reduct 8:8-9. https://doi.org/10.1016/j.ijdrr.2019.10131 7

22. DeweyJf C, Pitman WC (1989) Tectonic evolution of the India/ Eurasia collision zone. Eclogae Geol Helv 82:717-734

23. PMD N (2007) Seismic hazard analysis and zonation of Pakistan, Azad Jammu and Kashmir. Pakistan Meteorological Department and Norway Report

24. Farah A (1984) Earthquake risk in the Quetta area. Publication Directorate, Geological Survey of Pakistan

25. Khan SA, Shah MA, Qaisar M (2003) Seismic risk analysis of coastal area of Pakistan. Acta Seismol Sin 16(4):382-394. https ://doi.org/10.1007/s11589-003-0071-0

26. Mahmood I, Kidwai AA, Qureshi SN, Iqbal MF, Atique L (2015) Revisiting major earthquakes in Pakistan. Geol Today 31(1):3338. https://doi.org/10.1111/gto.12085

27. Plan QDAQU (1985) Quetta development authority in collaboration with National Engineering Services Pakistan QDA. NESPAK, Lahore

28. Ahmad N, Crowley H, Pinho R, Ali Q (2011) Seismic risk assessment and loss estimation of building stock of Pakistan. Ph.D. thesis, ROSE School-IUSS Pavia, University of Pavia, Pavia

29. Asian Development B, World B (2005) Preliminary damage and needs assessment-Pakistan 2005 earthquake. Asian Development Bank and World Bank Islamabad, Pakistan

30. Ainuddin S, Kumar Routray J, Ainuddin S (2014) People's risk perception in earthquake prone Quetta city of Baluchistan. Int J Disast Risk Reduct 7:165-175. https://doi.org/10.1016/j.ijdrr .2013.10.006

31. Ainuddin S, Routray JK (2012) Earthquake hazards and community resilience in Baluchistan. Nat Hazards 63(2):909-937. https ://doi.org/10.1007/s11069-012-0201-x

32. Rafi MM, Lodi SH, Varum H, Alam N, Ahmed M, Silveira D (2012) Assessment of seismic performance of adobe structures in Pakistan and Portugal. In: 15th world conference on earthquake engineering

33. Korkmaz HH, Korkmaz SZ, Donduren MS (2010) Earthquake hazard and damage on traditional rural structures in Turkey. Nat Hazards Earth Syst Sci 10(3):605-622. https://doi.org/10.5194/ nhess-10-605-2010

34. NDMP (2012) National disaster management plan

35. Pakistan Bureau of Statistics GoP (2017) Malakand protected area summary

36. BCP-07 (2007) Building code of Pakistan-seismic provisions. Ministry of Housing \& Works Islamabad, Islamabad

37. Alam N, Alam MS, Tesfamariam S (2012) Buildings' seismic vulnerability assessment methods: a comparative study. Nat Hazards 62(2):405-424. https://doi.org/10.1007/s11069-011-0082-4

38. Rajarathnam S, Santhakumar AR (2015) Assessment of seismic building vulnerability based on rapid visual screening technique aided by aerial photographs on a GIS platform. Nat Hazards 78(2):779-802. https://doi.org/10.1007/s11069-014-1382-2

39. Rautela P, Joshi GC, Bhaisora B, Dhyani C, Ghildiyal S, Rawat A (2015) Seismic vulnerability of Nainital and Mussoorie, two major Lesser Himalayan tourist destinations of India. Int J Disast Risk Reduct 13:400-408. https://doi.org/10.1016/j.ijdrr .2015.08.008

40. Nanda RP, Majhi DR (2014) Rapid seismic vulnerability assessment of building stocks for developing countries. KSCE J Civil Eng 18(7):2218-2226. https://doi.org/10.1007/s1220 5-014-0050-0

41. Grünthal G (1998) European macroseismic scale 1998. European Seismological Commission (ESC), Valletta

42. Agency FEM (2017) Rapid visual screening of buildings for potential seismic hazards: a handbook. Government Printing Office, New York 
43. Survey USG (2019) Slope based Vs30 map viewer. http://usgs. maps.arcgis.com/apps/webappviewer/index.html?id=8ac19 bc334f747e486550f32837578e1

44. Subramanian K, Velayutham M (2014) Seismic performance of lateral load resisting systems. Struct Eng Mech 51(3):487-502. https://doi.org/10.12989/sem.2014.51.3.487

45. Ozmen HB, Inel M, Meral E (2014) Evaluation of the main parameters affecting seismic performance of the RC buildings. Sadhana 39(2):437-450. https://doi.org/10.1007/s1204 6-014-0235-8

46. Avila L, Vasconcelos G, Lourenço PB (2018) Experimental seismic performance assessment of asymmetric masonry buildings. Eng Struct 155:298-314. https://doi.org/10.1016/j.engst ruct.2017.10.059

47. Oyguc R, Toros C, Abdelnaby AE (2018) Seismic behavior of irregular reinforced-concrete structures under multiple earthquake excitations. Soil Dyn Earthq Eng 104:15-32. https://doi. org/10.1016/j.soildyn.2017.10.002

48. Repapis C, Zeris C, Vintzileou E (2006) Evaluation of the seismic performance of existing RC buildings: li. A case study for regular and irregular buildings. J Earthq Eng 10(3):429-452. https://doi. org/10.1080/13632460609350604

49. ATC (2002) Rapid visual screening of buildings for potential seismic hazard: a handbook. The Federal Emergency Management Agency, Washington, DC

50. Bray JD, Luque R (2017) Seismic performance of a building affected by moderate liquefaction during the Christchurch earthquake. Soil Dyn Earthq Eng 102:99-111. https://doi. org/10.1016/j.soildyn.2017.08.011

51. Ahmad N, Shahzad A, Ali Q, Rizwan M, Khan AN (2018) Seismic fragility functions for code compliant and non-compliant RC SMRF structures in Pakistan. Bull Earthq Eng 16(10):4675-4703. https://doi.org/10.1007/s10518-018-0377-x

52. Briceño C, Moreira S, Noel MF, Gonzales M, Vila-Chã E, Aguilar R (2019) Seismic vulnerability assessment of a 17th century Adobe Church in the Peruvian Andes. Int J Archit Herit 13(1):140-152. https://doi.org/10.1080/15583058.2018.1497224

53. Yamane T (1967) Problems to accompany statistics: an introduction analysis. Harper \& Row, NewYork

54. Shahzada K, Khan AN, Elnashai AS, Ashraf M, Javed M, Naseer A, Alam B (2012) Experimental seismic performance evaluation of unreinforced brick masonry buildings. Earthq Spectra 28(3):1269-1290. https://doi.org/10.1193/1.4000073

55. Shahzada K, Ullah A, Khan AN, Naseer A, Ashraf M (2009) Sustainable buildings in district Dera Ismail Khan and adjoining areas: an experimental study. In: International disaster management conference

56. Maqsood ST, Schwarz J (2010) Building vulnerability and damage during the 2008 Baluchistan earthquake in Pakistan and past experiences. Seismol Res Lett 81(3):514-525. https://doi. org/10.1785/gssrl.81.3.514

57. Ahmad N, Ali Q, Ashraf M, Alam B, Naeem A (2012) Seismic vulnerability of the Himalayan half-dressed rubble stone masonry structures, experimental and analytical studies. Nat Hazards Earth Syst Sci 12(11):3441-3454. https://doi.org/10.5194/nhess $-12-3441-2012$

58. Doğangün A, Ural A, Livaoğlu R (2008) Seismic performance of masonry buildings during recent earthquakes in Turkey. In: The 14th world conference on earthquake engineering, pp 12-17

59. Ismail N, Khattak N (2016) Building typologies prevalent in Northern Pakistan and their performance during the 2015 Hindu Kush Earthquake. Earthq Spectra 32(4):2473-2493

60. Chourasia A, Bhattacharyya SK, Bhandari NM, Bhargava P (2016) Seismic performance of different masonry buildings: full-scale experimental study. J Perform Constr Facil 30(5):04016006. https ://doi.org/10.1061/(ASCE)CF.1943-5509.0000850

61. Naja MK, Baytiyeh H (2014) Towards safer public school buildings in Lebanon: an advocacy for seismic retrofitting initiative. Int J Disast Risk Reduct 8:158-165. https://doi.org/10.1016/j.ijdrr .2014.03.005

62. Ahmad Z, Shahzada K, Gencturk B, Naeem Khan A, Rehan R, Fahad M, Ashraf M, Ali Z (2015) Seismic capacity assessment of unreinforced concrete block masonry buildings in Pakistan before and after retrofitting. J Earthq Eng 19(3):357-382. https ://doi.org/10.1080/13632469.2014.963744

63. Ahmad N, Ali Q, Ashraf M, Khan AN, Alam B (2012) Performance assessment of low-rise confined masonry structures for earthquake induced ground motions. Int J Civil Struct Eng 2(3):851868. https://doi.org/10.6088/ijcser.00202030013

64. Mutch C (2018) The role of schools in helping communities copes with earthquake disasters: the case of the 2010-2011 New Zealand earthquakes. Environ Hazards 17(4):331-351. https ://doi.org/10.1080/17477891.2018.1485547

65. Dowrick DJ (2003) Earthquake risk reduction. Wiley, New York

Publisher's Note Springer Nature remains neutral with regard to jurisdictional claims in published maps and institutional affiliations. 